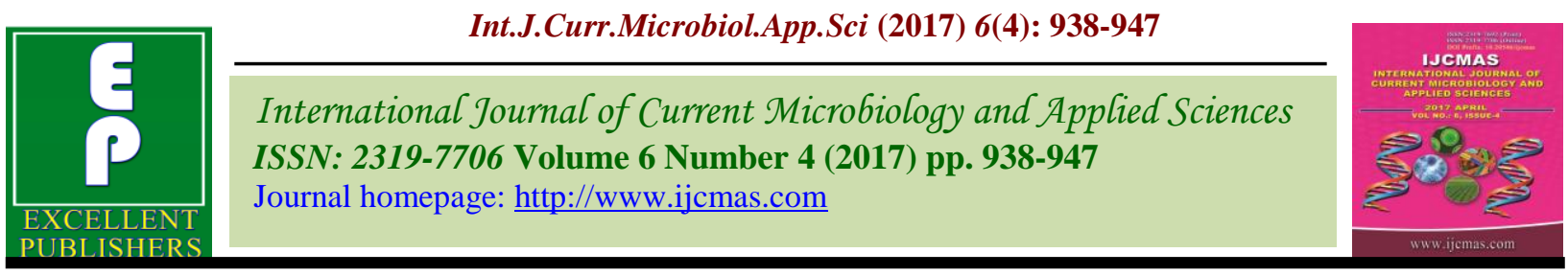

Original Research Article https://doi.org/10.20546/ijcmas.2017.604.118

\title{
Biosynthesis and Characterization of Silver Nanoparticles
}

\author{
Payal N. Agrawal* and Nikhilesh S. Kulkarni \\ Department of Microbiology, Microbiology Research Laboratory, R.A. College, \\ Washim-444505 (M.S.), India \\ *Corresponding author
}

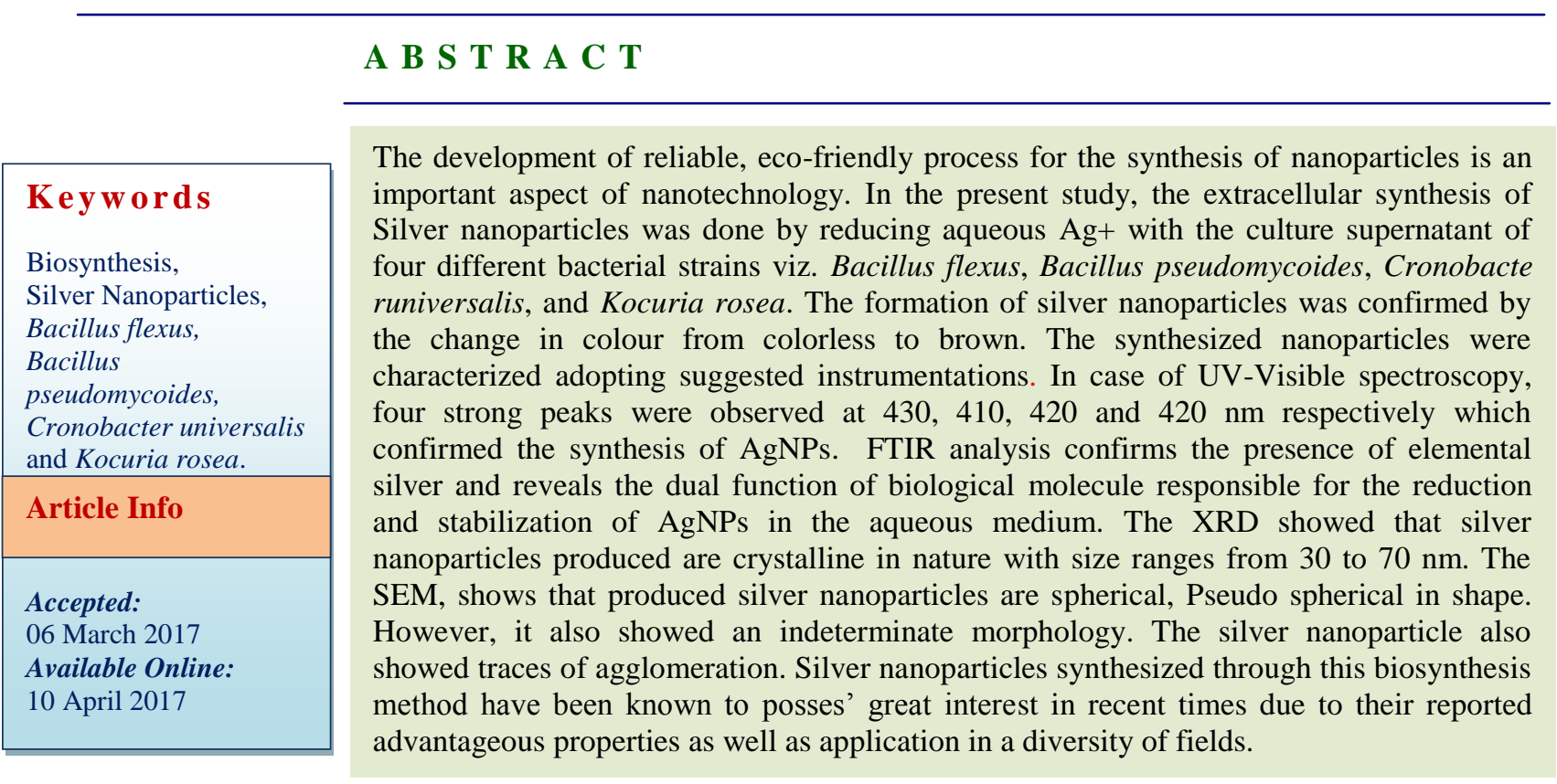

\section{Introduction}

Nanotechnology is the creation of functional materials, devices and system through control of matter on the nanometer length scale (1$100 \mathrm{~nm})$ and exploitation of novel phenomenon and properties at that length scale"(Nasa's definition). Nanotechnology, on the other hand, simply denotes the man-made use of these nano-sized particles, for industrial and medical purposes. Now-a-days we are using nanoproducts in various fields. Different types of nanomaterials like copper, zinc, titanium (Retchkiman-Schabes et al., 2006), magnesium, gold ( $\mathrm{Gu}$ et al., 2003), alginate (Ahmad et al., 2005) and silver have come up but silver nanoparticles have proved to be most effective as it has good antimicrobial efficacy against bacteria, viruses and other eukaryotic micro-organisms (Gong et al., 2007). Zhao and Stevens in 1998 worked on the antimicrobial activity of silver nanoparticles (Ag-NPs), which appears significantly high and also reported that Silver is more toxic element to microorganisms than many other metals. The synthesis of nanoparticles extensively studied by using chemical and physical methods, but the development of reliable technology to produce nanoparticles is an important aspect 
of nanotechnology. Many studies have reported successful synthesis of silver nanoparticle using microorganisms and biological systems (Korbekandi et al., 2009; Sastry et al., 2003; Iravani, 2011).

It was reported that highly stable silver nanoparticles $(40 \mathrm{~nm})$ could be synthesized by bioreduction of aqueous silver ions with a culture supernatant of some non pathogenic and pathogenic Bacteria viz. Bacillus licheniformis (Kalishwaralal et al., 2008b), B. subtilis (Saifuddin et al., 2009), Pseudomonas stutzeri AG259 (Klaus et al., 1999), Klebsilla pneumoniae (Mokhtari et al., 2009), E. coli, Enterobacter cloacae (Shahverdi et al., 2007) and Lactobacillus (Nair and Pradeep, 2002).

Many studies have enlightened the biological synthesis of Silver nanoparticles from bacteria; however, biological synthesis of silver nanoparticles by using Bacterial isolates was scantily studied. Hence, the present study was carried out on synthesis of Silver nanoparticles by bacteria. The generated nanoparticles were characterized by an instrumental analysis viz., UV- Visible spectroscopy, Fourier transform infrared spectroscopy (FT-IR), Scanning electron microscopy (SEM) and X-ray diffraction (XRD).

\section{Materials and Methods}

\section{Biosynthesis and characterization of silver nanoparticles}

The silver nanoparticles were synthesized from four different silver resistant bacterial isolates viz. Bacillus flexus, Bacillus pseudomycoides, Cronobacter universalis, and Kocuria rosea., adopting the method suggested by Das et al., (2013) with slight modifications.

\section{Preparation of bacterial cell free extract}

For the biosynthesis of silver nanoparticle, selected bacterial isolates were separately inoculated in to $250 \mathrm{ml}$ conical flasks containing $100 \mathrm{ml} \mathrm{LB}$ broth and maintained in incubatory shaker (Remi make) at $220 \mathrm{rpm}$. The growth parameters were adjusted at $\mathrm{pH} 6$ and Temperature $40^{\circ} \mathrm{C}$. Followed by incubation the enriched cultures were subjected to ultra centrifugation at $20,000 \mathrm{rpm}$ for 10minutes. The supernatant material was separated out and use as crude source of reductase enzyme for the extracellular synthesis of nanoparticles.

\section{Biosynthesis of silver nanoparticles}

In a typical biosynthesis production scheme of silver nanoparticles, $2 \mathrm{ml}$ of supernatant from each bacterial culture was mixed separately with $100 \mathrm{ml}$ of $1 \mathrm{mM}$ aqueous solutions of filtered sterilized $\mathrm{AgNO}_{3}$, in $250 \mathrm{ml}$ conical flasks. Further the reaction mixture is placed at $150 \mathrm{rpm}$ in incubatory shaker (Remi make) shaker at $37^{\circ} \mathrm{C}$ up to 72 hours and allowed for reduction. The set without $\mathrm{AgNO}_{3}$ was maintained as Control and use to compare with the test samples.

\section{Extraction and Purification of Silver Nanoparticles}

The silver nanoparticles were purified by three successive ultra Centrifugations at $20,000 \mathrm{rpm}$ for 15 minutes at $4^{0} \mathrm{C}$, the supernatant were separated out. The supernatant clear suspension was redispersed in sterile deionised water to remove the residual biological molecules. The process of centrifugation and redispersion in sterile deionised water was repeated thrice for complete removal of the residual entities from the silver nanoparticles. The purified solution was then dried using hot air oven at $60^{\circ} \mathrm{C}$ for overnight (Nagarajan and Kuppusamy, 2013). 
The dried powder of Silver nanoparticles was then mixed with $10 \mathrm{ml}$ of deionized water and kept on a sonicator to prevent aggregation of molecules and further used for Characterization.

\section{Characterization of silver nanoparticles}

\section{UV- Visible spectroscopic analysis}

During the assay, approximately $1 \mathrm{ml}$ of sample (crude extract) was withdrawn in standard quartz cuvette $(1 \mathrm{~cm})$. The absorbance spectra of the AgNPs were analyzed by determining the maximum absorbance of the samples in the range of 350 to $450 \mathrm{~nm}$, with UV-Vis spectrometer Shimadzu-UV 1800 using double deionized distilled water as a reference.

\section{FT-IR analysis}

The characterization of functional groups on the surface of AgNPs was investigated by FTIR analysis (Nicklet 380). The samples were prepared by dispersing the synthesized AgNPs uniformly in a matrix of dry $\mathrm{KBr}$ (in the ratio of $1: 100$ ), compressed to form an almost transparent disc FTIR spectrum of all samples was recorded in Nicolet Impact 400FT-IR spectrophotometer instrument with a diffuse reflectance mode (DRS8000) attachment. The spectra were scanned in the range of $4000-400 \mathrm{~cm}^{-1}$ with the resolution of $4 \mathrm{~cm}^{-1}$. The spectra thus obtained were used to determined the associated compounds with nanoparticles (Aguilar-Mendez et al., 2011)

\section{XRD analysis}

XRD measurements of the reduced AgNPs perform were recorded by using D8 advanced model X-ray diffractometer instrument made in Bruker. In XRD Diffractometer, all the synthesized samples were operating at a voltage of $40 \mathrm{kV}$ and current of $30 \mathrm{~mA}$ with $\mathrm{Cu} \mathrm{K}(\alpha)$ radiation to determine the crystalline phase and material identification.
The samples were scanned in the 20ranges of 10-80 degree in continuous scan mode. The Scan rate was adjusted at $0.20 /$ second. The crystalline size of the synthesized silver nanoparticles was determined from X-ray line broadening using the Scherrer's equation formula reported by Cullity and Rita John (2009),

$\mathrm{D}=0.9 \lambda / \beta \cos \theta \ldots \ldots(1)$

Where ' $\lambda$ is wave length of X-Ray $(0.1541$ $\mathrm{nm}$ ), $\beta$ is FWHM (full width at half maximum), $\theta$ is the diffraction angle and ' $D$ ' is particle diameter size.

\section{SEM analysis}

The Morphological characterization of the samples was done using JEOL 5400. Silver nanoparticles in its powder form were separately sonicated with distilled water further the small amount of sample was spread on glass slide and allow drying and a thin film of gold was coated to make the sample conductive. The machine was operated at a vacuum and accelerated voltage of the microscope was kept in the range 30 $\mathrm{kv}$. The images thus obtained were used for determination of particle shape (Pavani et al., 2013).

\section{Results and Discussion}

\section{Biosynthesis of silver nanoparticles}

In all the test samples AK1, AK2, AK3 and AK4 the Silver nanoparticles were produced showing the positive reduction of Ag+ ions. This has been confirmed by visualize change in color from colourless to dark brown. Further the Silver nanoparticles were separated out by ultracentrifugation process. The purified solutions were then dried and all four AgNPs powder samples (viz. AK1, AK2, AK3 and AK4) were subjected for characterization. 


\section{Characterization of synthesized Silver Nanoparticles}

\section{UV- Visible Spectrophotometric analysis}

The reduction of Silver salt to their respective silver ions was monitored by UV-Visible spectrum, presented in Table (1) and graphically represented in figure 1. Four strong peaks were observed at $430 \mathrm{~nm}$, $410 \mathrm{~nm}, 420 \mathrm{~nm}$ and $420 \mathrm{~nm}$ confirming the synthesis of AgNPs using four different bacterial strains (viz. Bacillus flexus, Bacillus pseudomycoides, Cronobacter universalis and Kocuriarosea), the results on the obtained UV-Visible spectrum are in accordance with the revived reports of Henglein (1993), who reported that a SPR peak located between 410 and 440nm has been observed for AgNPs and is well documented for $\mathrm{Ag}$ (metal) nanoparticles with sizes from 2 to $100 \mathrm{~nm}$. Our findings also correlated with the reports of He et al., (2007) and Portner (2007).

\section{FT-IR spectroscopy analysis}

The results of FTIR for all four AgNPs samples (viz. AK1, AK2, AK3 and AK4) were represented in figure (2.1 to 2.4). In case of Sample AK1 and AK3, the band seen at 3398.02 and 3398.29 were assigned to $\mathrm{NH} 2$ stretching of primary amide, band at 1530.38 and 1530.55 corresponds to N-H bending and $\mathrm{C}-\mathrm{N}$ stretching of secondary amide, where as the band at 1143.48 and 1143.22 corresponds to $\mathrm{C}-\mathrm{N}$ stretching of aliphatic amine respectively. In sample AK 1 alone the band at 773.77 is characteristic of $\mathrm{NH} 2$ wagging and twisting. Where as In case of Sample AK2 and AK4, the band at 3231.19 and 3285.24 were assigned to $\mathrm{N}-\mathrm{H}$ stretching of secondary amide respectively, in sample AK4 the band at 1078.85, 1018.21 correspond to $\mathrm{C}-\mathrm{N}$ stretching of aromatic amines. The bands obtained were compared with band range given by Stuart (2004). It has also been reported earlier by Gole et al., (2001), that protein can bind to silver nanoparticle either through their free amine groups or cysteine residues. Therefore stabilization of silver nanoparticles by proteins is a clear possibility. Hence the FTIR analysis confirms the presence of elemental silver, in biosynthesized samples of AgNPs as it is generated from inorganic silver salt and reveals the dual function of biological molecule responsible for the reduction and stabilization of $\mathrm{AgNps}$ in the aqueous medium. Our results correlate with Senapati et al., (2005), Jeeven et al., (2012) and Vijayaraj et al., (2012) they also reported the presence of silver nanoparticles by determining the interaction between silver salt and protein molecules.

\section{XRD analysis}

The XRD pattern obtained for all four AgNPS samples (viz. AK1, AK2, AK3 and AK4) were represented in figure (3.1 to 3.4) Comparisons of XRD spectrum with the standard powder diffraction card of Joint Committee on Powder Diffraction Standards (JCPDS), silver file No. 04-0 783, confirms that the silver nanoparticles found in the present study were in the form of nanocrystals as evident from the peak at $2 \theta$ values of all the samples, these all values are correspond to (111), (200), (220), (311) respectively for silver represented in table 2 . Pande et al., (2012) reported that these typical XRD peak occurs due to the presence of Face centered cubic (fcc) of the crystalline silver nanoparticles. 
Table.1 UV-Visible absorbance spectra of synthesized silver nanoparticles

\begin{tabular}{|c|c|c|c|c|}
\hline $\begin{array}{c}\text { Optical } \\
\text { (nm)density } \\
\text { at }\end{array}$ & \multicolumn{4}{|c|}{ Mean optical density of synthesized silver } \\
nanoparticles
\end{tabular}

Table.2 Peak indexing from $\mathrm{d}$ - spacing and grain size of Silver nanopowder

\begin{tabular}{|c|c|c|c|c|c|c|c|}
\hline $2 \theta$ & D & $1000 / d^{2}$ & $\begin{array}{l}\left(1000 / d^{2}\right) \\
/ 60.62\end{array}$ & Hkl & $\begin{array}{l}\text { FWHM } \\
(\beta)\end{array}$ & $\beta \cos \theta$ & $\begin{array}{l}\text { Size of particle } \\
\text { (D) } \mathrm{nm}\end{array}$ \\
\hline \multicolumn{8}{|c|}{ Sample AK1 } \\
\hline 37.91 & 2.371 & 177.904 & 2.934 & 111 & 0.0041 & 0.00407 & 34 \\
\hline 43.98 & 2.056 & 236.574 & 3.902 & 200 & 0.0048 & 0.00479 & 29 \\
\hline 64.21 & 1.449 & 476.417 & 7.859 & 220 & 0.0038 & 0.00292 & 47 \\
\hline 77.20 & 1.234 & 657.030 & 10.838 & 311 & 0.0034 & 0.00210 & 66 \\
\hline \multicolumn{8}{|c|}{ Sample AK2 } \\
\hline 38 & 2.366 & 178.667 & 2.947 & 111 & 0.0041 & 0.00405 & 34 \\
\hline 44.15 & 2.049 & 238.208 & 3.929 & 200 & 0.0048 & 0.00478 & 29 \\
\hline 64.36 & 1.446 & 478.468 & 7.892 & 220 & 0.0038 & 0.00274 & 50 \\
\hline 77.28 & 1.233 & 657.894 & 10.852 & 311 & 0.0034 & 0.00200 & 69 \\
\hline \multicolumn{8}{|c|}{ Sample AK3 } \\
\hline 37.92 & 2.370 & 178.062 & 2.937 & 111 & 0.0041 & 0.00407 & 34 \\
\hline 44.09 & 2.052 & 237.529 & 3.918 & 200 & 0.0048 & 0.00479 & 29 \\
\hline 64.28 & 1.447 & 477.783 & 7.881 & 220 & 0.0038 & 0.00284 & 49 \\
\hline 77.17 & 1.235 & 655.737 & 10.817 & 311 & 0.0034 & 0.00214 & 65 \\
\hline \multicolumn{8}{|c|}{ Sample AK4 } \\
\hline 37.91 & 2.371 & 177.904 & 2.934 & 111 & 0.0041 & 0.00407 & 34 \\
\hline 43.98 & 2.056 & 236.574 & 3.902 & 200 & 0.0048 & 0.00479 & 29 \\
\hline 64.21 & 1.449 & 476.417 & 7.859 & 220 & 0.0038 & 0.00292 & 47 \\
\hline 77.20 & 1.234 & 657.030 & 10.838 & 311 & 0.0034 & 0.00210 & 66 \\
\hline
\end{tabular}


Fig.1

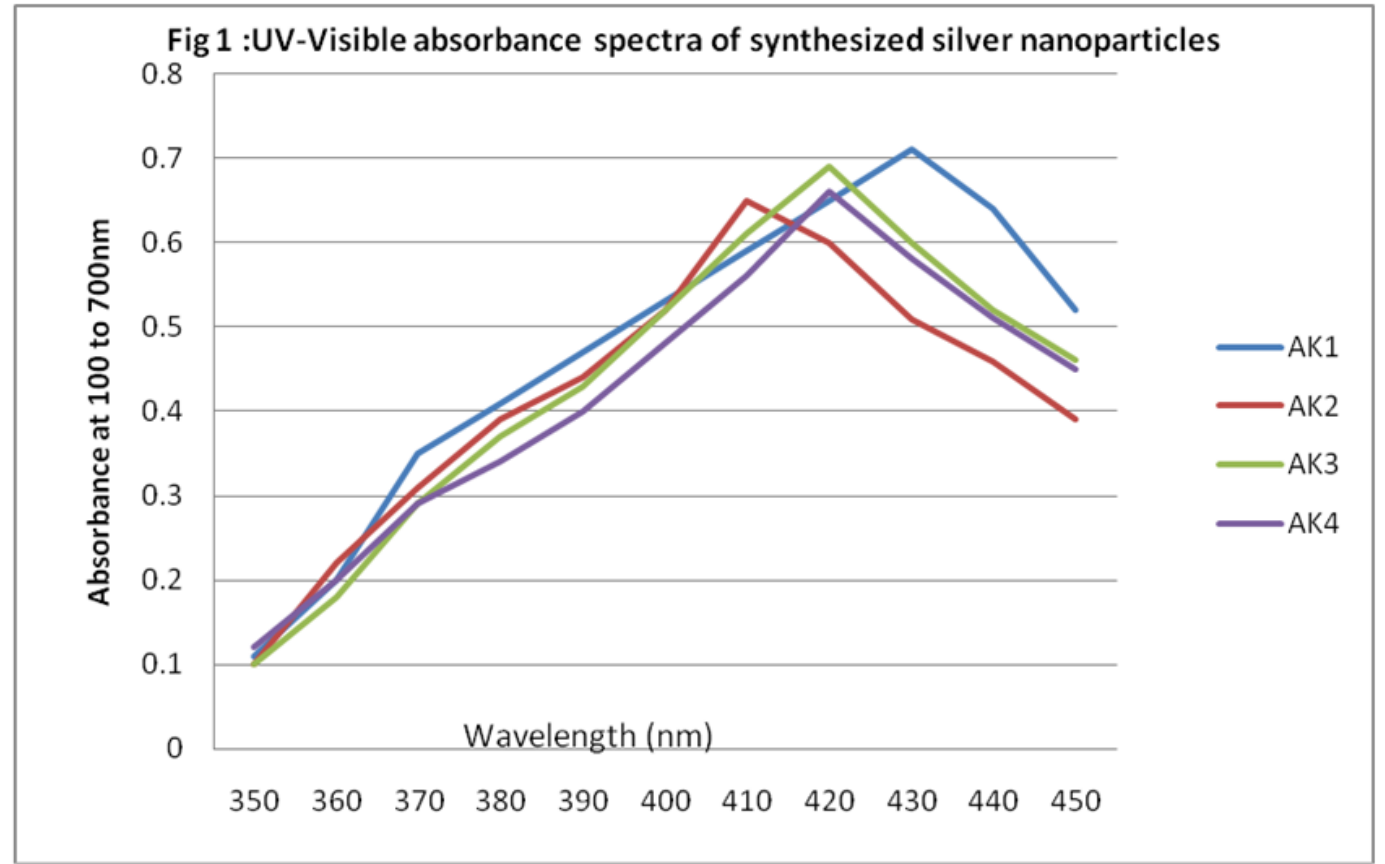

Fig.2.1-2.4 FTIR Spectrum of Silver nanoparticles synthesized from bacteria Bacillus flexus, Bacillus pseudomycoides, Cronobacter universalis and Kocuria rosea respectively
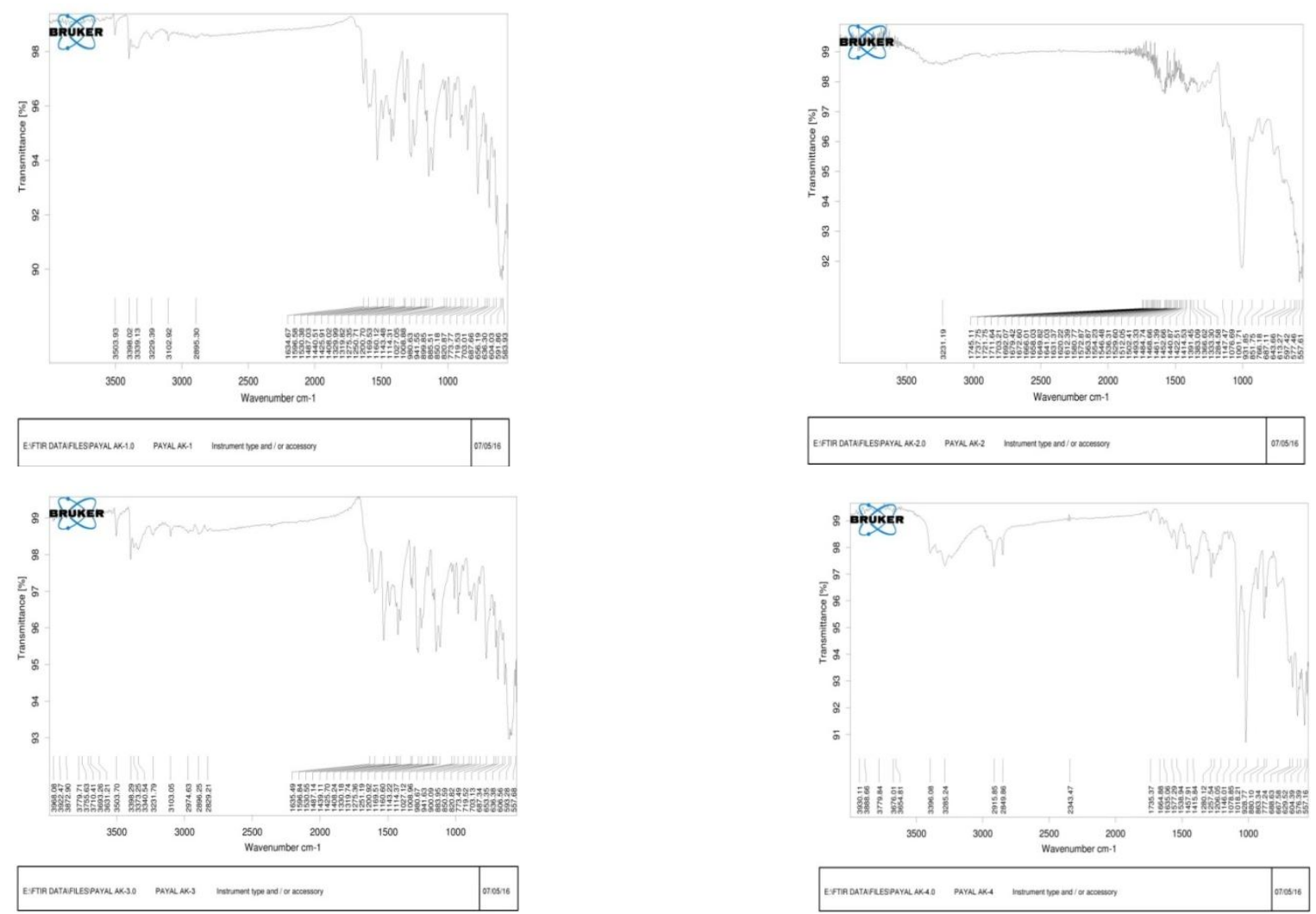
Fig.3.1-3.4 XRD Spectrum of Silver nanoparticles synthesized from bacteria Bacillus flexus, Bacillus pseudomycoides, Cronobacter universalis and Kocuria rosea respectively

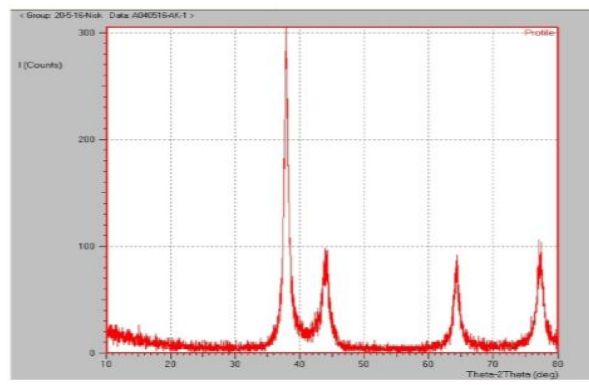

AK1

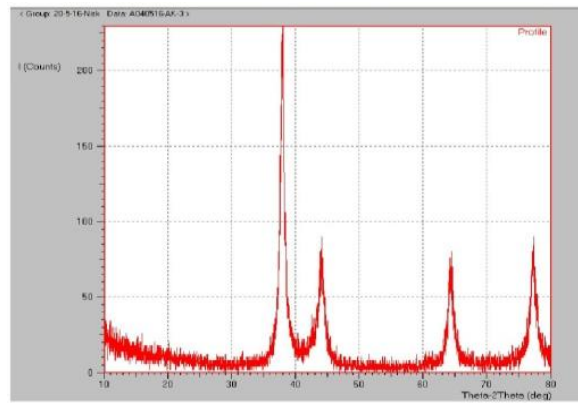

AK3

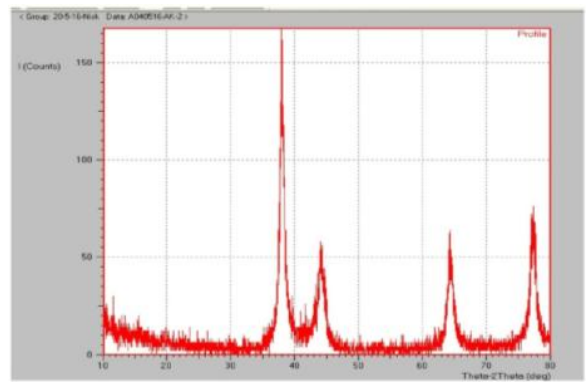

AK2

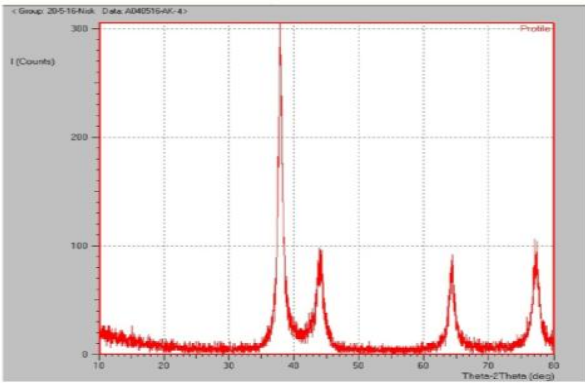

AK4

Fig.41.-4.4 SEM images of Silver Nanoparticles synthesized from bacteria bacteria Bacillus flexus, Bacillus pseudomycoides, Cronobacter universalis and Kocuria rosea respectively

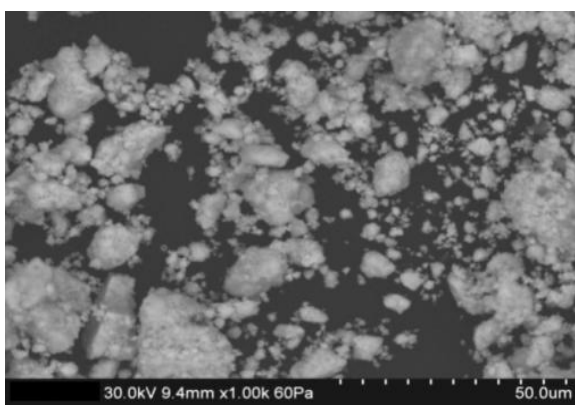

AK1

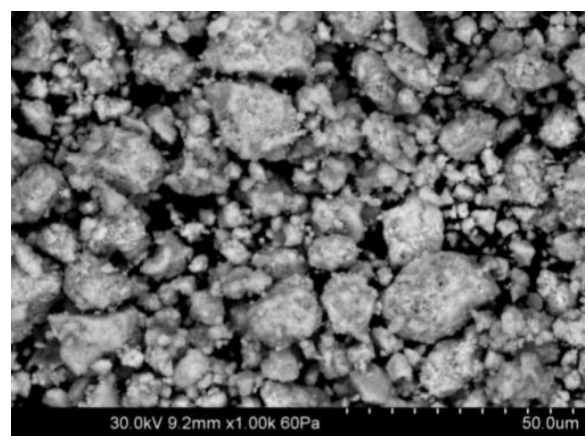

AK3

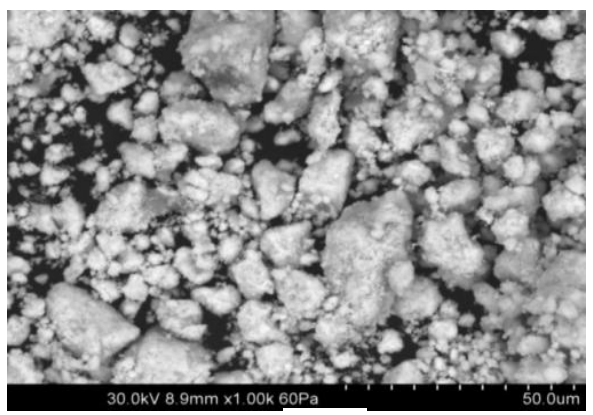

AK2

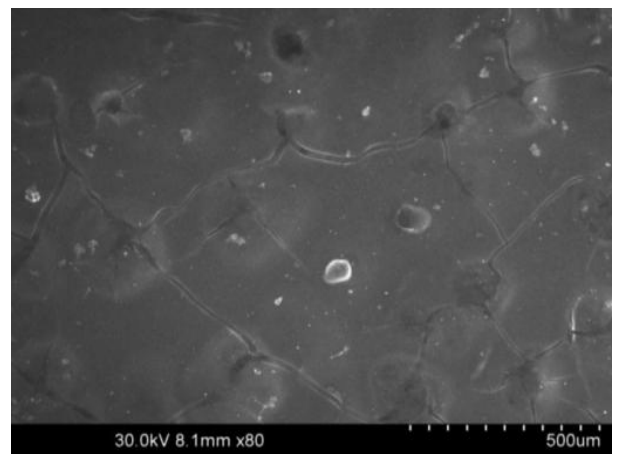

AK4 
The high intense peak for FCC materials is generally (111) reflection, which is observed in all the samples. The XRD shows that silver nanoparticles formed are crystalline. The results are in correlation with the reports of, Amrut et al., (2010), Prakash et al., (2010), Prakash et al., (2011), Jeevan et al., (2012) and Manivasagan et al., (2013). The calculated particle size details are displayed in Table (2), it was observed that all the samples contain four different sizes of Silver nanoparticle with size ranges from 30 to 70 $\mathrm{nm}$. The overall result of XRD was correlated with the results of Theivasanthi and Alagar (2010).

\section{SEM analysis}

The image shows representative SEM images recorded at high magnifications of the biosynthesized silver nanoparticles, shown in Figure (4.1 to 4.4) in case of Sample AK1, $\mathrm{AK} 2, \mathrm{AK} 3$ and AK4. It was observed that the produced silver nanoparticles that present in samples were scattered as well as in aggregates of varying sizes. It was observed that produced silver nanoparticles are spherical, Pseudo spherical and of undefined morphology with traces of agglomeration. The results on the present studies on the surface morphology are in accordance with the experimental findings of Malarkodi and Annadurai (2012). They reported the spherical, Pseudo spherical and agglomeration as the surface morphological shapes. The scanning images also showed the agglomeration it may be due to the fact that silver nanoparticles have the tendency to agglomerate due to their high surface energy and high surface tension of the ultrafine nanoparticles. Larger size agglomeration was reported by Theivasanthi and Alagar (2010).

This work demonstrates the simple approach to achieve an eco-friendly way for the biosynthesis of Silver nanoparticles from bacterial isolates viz. Bacillus flexus, Bacillus pseudomycoides, Cronobacter universalis, and Kocuriarosea. Silver nanoparticles synthesized by the bacterial strains indicates the rapid synthesis of nanoparticles and hence perhaps to be used in biosynthesis process for large scale production. Several studies have reported the synthesis of silver nanoparticles using different bacterial strains. However, the reports in present study on Silver nanoparticles producing isolates could not be traced hence maybe consider as value added account.

\section{References}

Aguilar Mendez, M.A., E.S. Martin- Martinez, L. Ortega - Arroyo, G. Cobiaan - Portillo and E. Saanchez Espindola. 2011. Synthesis and Characterization of Silver nanoparticles: effect on Phytopathogen Colletotrichum gloesporioides. J. Nanopart. Res., 13: 2525-2532.

Ahmad, Z., Pandey, R., Sharma, S., Khuller, G.K. 2005. Alginate nanoparticles as antituberculosis drug carriers: formulation development, pharmacokinetics and therapeutic potential. Ind. J. Chest Dis. Allied Sci., 48: 171-6.

Amrut, S., Lanje, Satish, J., Sharma, Ramchandra, B., Pode. 2010. J. Chem. Pharm. Res., 2(3): 478.

Stuart, B. 2004. Infrared Spectroscopy: Fundamentals and Applications., page 47.

Cullity B.D.2004. Book of Elements of X-ray Diffraction, Addison-Wesley Company, USA.

Das Vidhya Lakshmi, Roshmi Thomas, Rintu, T., Varghese, E.V., Soniya, Jyothis Mathew, E.K. Radhakrishnan. 2013. Extracellular synthesis of silver nanoparticles by the Bacillus strain CS 11 isolated from industrialized area, 3 Biotech, doi:10.1007/s13205-013-0130-8.

Gole, A., Dash, C., Ramakrishnan, V., Sainkar, S.R., Mandale, A.B. et al. 2001. Pepsin Gold colloid conjugates: Preperation, Characterization and enzymatic, 
Langmuir, 17: 1674-1679.

Gong, P., Li, H., He, X., Wang, K., Hu, J., Tan, W., et al. 2007. Preparation and antibacterial activity of $\mathrm{Fe} 3 \mathrm{O} 4 @ \mathrm{Ag}$ nanoparticles. Nanotechnol., 18: 604-11.

Gu, H., Ho, P.L., Tong, E., Wang, L., Xu, B. 2003. Presenting vancomycin on nanoparticles to enhance antimicrobial activities. Nano Lett., 3(9): 1261-3.

He, S., Guo, Z., Zhang, Y., Zhang, S., Wang, J., $\mathrm{Gu}, \quad$ N. 2007. Biosynthesis of gold nanoparticles using the bacteria Rhodopseudomonas capsulate. Mater. Lett., 61: 3984-3987

Henglein, A. 1993. Physicochemical properties of small metal particles in solution: microelectrode reactions, chemisorption, composite metal particles, and the atomto-metal transition. J. Phys. Chem. B., 97(21): 5457-5471.

Iravani, S. 2011. Green synthesis of metal nanoparticles using plants. Green Chem., 13: 2638-2650.

Jeevan, P., Ramya, K., Edith Rena, A. 2012. Extracellular biosynthesis of silver nanoparticles by culture supernatant of Pseudomonas aeruginosa. Indian $J$. Biotechnol., 11: 72-76.

Kalishwaralal, K., Deepak, V,. Ramkumarpandian, S., Nellaiah, H. and Sangiliyandi, G. 2008b. Extracellular biosynthesis of silver nanoparticles by the culture supernatant of Bacillus licheniformis. Mater. Lett., 62: 44114413.

Klaus, T., Joerger, R., Olsson, E. and Granqvist, C.Gr. 1999. Silver-based crystalline nanoparticles, microbially fabricated. Proc. Natl. Acad. Sci. USA, 96: 1361113614.

Korbekandi, H., Iravani, S. and Abbasi, S. 2009. Production of nanoparticles using organisms. Crit. Rev. Biotechnol., 29: 279-306.

Malarkodi, C., Annadurai, G. 2012. A novel biological approach on extracellular synthesis, and characterization of semiconductor zinc sulfide nanoparticles, Appl. Nanosci.
Manivasagan, P., Venkatesan, J., Kalimuthu, S., Kannan, Kim, S.K. 2013. Biosynthesis, Antimicrobial and Cytotoxic effect of Silver Nanoparticles using a Noval Nocardiopsis spp. MBRC-1: Biomed Res. Int. Article ID 287638, 9 pages.

Mokhtari, N., Daneshpajouh, S., Seyedbagheri, S., Atashdehghan, R., Abdi, K., Sarkar, S, Minaian S, Shahverdi H.R. and Shahverdi A.R. 2009. Biological synthesis of very small silver nanoparticles by culture supernatant of Klebsiella pneumonia: The effects of visible-light irradiation and the liquid mixing process. Materials Res. Bull., 44: 1415-1421.

Nagarajan, S. and K.A. Kuppusamy. 2013. Extracellular synthesis of zinc oxide nanoparticles using seaweeds of gulf of mannar, India. J. Nanobiotechnol., 11(39).

Nair, B. and Pradeep, T. 2002. Coalescence of nanoclusters and formation of submicron crystallites assisted by Lactobacillus strains. Crystal Growth and Design, 2: 293- 298.

Pavani, K.V., S. Nandigam, P. Guntur and S. Tandale. 2013. Synthesis of Copper Nanoparticles by Aspergillus Sp. J. letters in Applied Nano BioSci., 2(2): 110 - 113.

Pörtner, R, Giese, C. 2007. An Overview on Bioreactor Design, Prototyping and Process Control for Reproducible ThreeDimensional Tissue Culture. In: Marx and Sandig: Drug Testing In Vitro Breakthroughs and Trends in Cell Culture Technology. Wiley-VCH Verlag $\mathrm{GmbH}$ and Co. KgaA, Weinheim.

Prakash, A., Sharma, S., Ahmad, N., Ghosh, A., Sinha, P. 2010. Bacteria mediated extracellular synthesis of metallic nanoparticles. Int. Res. J. Biotechnol., 5: 71-9.

Prakash, A., Sharma, S., Ahmad Naheed, Ghosh. A., Sinha, P. 2011. Synthesis of AgNPs by Bacillus cereus Bacteria and their antibacterial Potential. $J$. Biomaterials and Nanobiotechnol., 2: 156-162.

Retchkiman-Schabes, P.S., Canizal, G., 
Becerra-Herrera, R., Zorrilla, C., Liu, H.B., Ascencio, J.A. 2006. Biosynthesis and characterization of $\mathrm{Ti} / \mathrm{Ni}$ bimetallic nanoparticles. Opt. Mater., 29: 95-9.

Saifuddin, N., Wang, W.C., Nur Yasumira, A.A. 2009. Rapid biosynthesis of silver nanoparticles using culture supernatant of bacteria with microwave irradiation, $E J$. Chem., 6(2): 61-70.

Sastry, M., Ahmad, A., Khan, M.I. and Kumar, R. 2003. Biosynthesis of metal nanoparticles using fungi and actinomycete, Curr. Sci., 85: 162-170.

Senapati, S., Ahmad, A., Khan, M.I., Sastry, Kumar, R. 2005. Extracellular biosynthesis of bimetallic au-Ag alloy nanoparticles. Small, 1(5): 517-20.

Shahverdi, A.R., Minaeian, S., Shahverdi H.R, Jamalifar H. and Nohi A. 2007. Rapid synthesis of silver nanoparticles using culture supernatants of Enterobacteria: A novel biological approach. Process Biochem., 42: 919-923.

Theivasanthi, T. and M. Alagar. 2010. Electrolytic Synthesis and Characterizations of Silver Nanopowder. Vijayaraj, D, Anarkali, J., Rajathi, K. and Sridhar, S. 2012. Green synthesis and Characterization of silver nanoparticles from the leaf extract of Aristolochia Bracteatav and its antimicrobial efficacy. Int. J. Nanomaterials and Biostructeres, $2(2) ; 11-15$.

Zhao, G.J., Stevens, S.E. 1998. Multiple parameters for the comprehensive evaluation of the susceptibility of Escherichia coli to the silver ion. Bimetals, 11: 27-32.

\section{How to cite this article:}

Payal N. Agrawal, Nikhilesh S. Kulkarni. 2017. Biosynthesis and Characterization of Silver Nanoparticles. Int.J.Curr.Microbiol.App.Sci. 6(4): 938-947.

doi: https://doi.org/10.20546/ijcmas.2017.604.118 